\title{
Outcomes for 18 to 25 -year-olds with borderline personality disorder in a dedicated young adult only DBT programme compared to a general adult DBT programme for all ages 18
}

Lyng, Jim; Swales, Michaela A; Hastings, Richard P; Millar, Tracy; Duffy, Daniel

\section{Early Intervention in Psychiatry}

DOI:

10.1111/eip.12808

Published: 01/02/2020

Peer reviewed version

Cyswllt i'r cyhoeddiad / Link to publication

Dyfyniad o'r fersiwn a gyhoeddwyd / Citation for published version (APA):

Lyng, J., Swales, M. A., Hastings, R. P., Millar, T., \& Duffy, D. J. (2020). Outcomes for 18 to 25year-olds with borderline personality disorder in a dedicated young adult only DBT programme compared to a general adult DBT programme for all ages 18. Early Intervention in Psychiatry, 14(1), 61-68. https://doi.org/10.1111/eip.12808

\footnotetext{
Hawliau Cyffredinol / General rights

Copyright and moral rights for the publications made accessible in the public portal are retained by the authors and/or other copyright owners and it is a condition of accessing publications that users recognise and abide by the legal requirements associated with these rights.

- Users may download and print one copy of any publication from the public portal for the purpose of private study or research.

- You may not further distribute the material or use it for any profit-making activity or commercial gain

- You may freely distribute the URL identifying the publication in the public portal ?
}

Take down policy

If you believe that this document breaches copyright please contact us providing details, and we will remove access to the work immediately and investigate your claim. 
Title: Outcomes for 18-25 year olds with borderline personality disorder in a dedicated young adult only DBT programme compared to a general adult DBT programme for all ages $18+$ 
Running title: Outcomes for young adult (18-25 yrs) DBT with BPD 


\section{Authorship:}

\section{Corresponding Author:}

\section{James Lyng, PhD}

Senior Counselling Psychologist

Cluain Mhuire Community Mental Health Services,

Dept of Psychology, Cluain Mhuire Family Centre

Newtownpark Avenue, Blackrock, Ireland

Email: jlyng@tcd.ie

Other Authors:

Michaela Swales, PhD

Consultant Clinical Psychologist \& Reader in Clinical Psychology

School of Psychology, Bangor University

Adeilad Brigantia, Penrallt Rd.

Bangor, Gwynedd, LL57 2AS, United Kingdom

Email: m.swales@bangor.ac.uk

\section{Richard P Hastings, PhD}

Deputy Director, Professor, and Cerebra Chair of Family Resarch University of Warwick

CEDAR

New Education Building, Westwood Campus

Coventry, West Midlands, CV4 7AL, United Kingdom

Email: r.hastings@warwick.ac.uk 


\section{Tracy Millar, DClinPsych}

Consultant Clinical Psychologist

South Eastern Health and Social Care Trust

DBT Team

Dundonald, BT16 1RH, United Kingdom

Email: millar009@googlemail.com

\section{Daniel J Duffy, MSc}

PhD Student \& Research Coordinator

School of Psychology

Trinity College Dublin, Ireland.

Email: Daniel.duffy@ silvercloudhealth.org 
Aims. Early intervention (EI) for borderline personality disorder (BPD) may carry significant social and clinical benefits. We aimed to evaluate an EI-informed community-based Dialectical Behaviour Therapy (DBT) programme delivered exclusively to young adults with BPD.

Methods. We describe a naturally occurring non-equivalent, quasi-experimental comparison of outcomes for young adults (18-25 years) with BPD following one year of treatment in either a young adult only DBT programme or a general adult DBT programme (18+ years). 24 young adults enrolled in a community-based young adult DBT programme open only to 18 to 25 year olds with BPD. Another 13 young adults, also 18-25 years, enrolled in a general adult DBT programme open to all ages above 18 years. Both treatment conditions offered all modes of standard DBT for one year. Participants completed a battery of selfreport measures on mental health symptoms at baseline and again at treatment completion after one year. Discharge rates at two years post-treatment completion were also recorded. Results. Better outcomes were found on borderline symptom severity and general psychopathology among completers of young adult DBT, with a large effect size for treatment condition as well as greater clinically significant change. Discharge rates from mental health services 24 months later were also higher for completers of young adult DBT. Conclusions. There may be advantages in delivering DBT to young adults in an age-specific, EI programme, possibly due to group cohesion. Methodological limitations apply, such as small sample size and non-randomisation. Further controlled research is needed.

Keywords: Borderline personality disorder, dialectical behaviour therapy, young adult, early intervention 


\section{Introduction}

There is a high prevalence of mental health problems among young adults, with three in four lifetime mental health disorders having an initial onset prior to 25 years (Eckersley, 2011; Kessler et al., 2005). Yet, young adults have low levels of engagement with mental health services and high rates of treatment dropout (Edlund et al., 2002; Reneses, Munoz, \& LopezIbor, 2009). Many factors are likely to contribute to this dilemma, among them the division between child and adult services in many countries at precisely the point where the need for developmentally sensitive support is pronounced (Murcott, 2012; Patton, 1996), and a lower priority given to treating young adults in adult services due to more severe presentations of others accessing care alongside a palliative bias in adult services (Callaly, 2014; Paul, Street, Wheeler, \& Singh, 2015). This situation represents missed opportunities for arresting the progression of chronic, disabling, and costly problems, not to mention high levels of human suffering (McGorry, 2011).

A promising alternative to the status quo of mental health service provision for young adults can be found in early intervention (EI) programmes for psychosis targeted at older adolescents and young adults (Jackson \& McGorry, 2009). Such EI programmes are designed to increase clinician and community awareness of illness, coupled with assertive intervention using established treatments before problems become more severe (Lyons \& Melton, 2005). Improvements in engagement, prognosis, illness-burden, and costeffectiveness have all been demonstrated in EI programmes for psychosis (Hegelstad et al., 2012; McGorry, 2015). EI might contribute to better outcomes for young adults with other mental health problems, but few data are available on dedicated EI programmes besides those for psychosis (Birleson, Luk, \& Mileshkin, 2001; McGorry, Bates, \& Birchwood, 2013; McGorry, Goldstone, Parker, Rickwood, \& Hickie, 2014). 
Borderline personality disorder (BPD) among young adults is an obvious candidate for EI owing to the typical adolescent onset of BPD and the serious and enduring nature of the disorder which is associated with affective instability, unstable interpersonal relationships, cognitive impairments, and impulsivity (Chanen \& McCutcheon, 2014; Moran et al., 2012). The general prevalence of BPD in the community has been reported at $1 \%$ (Coid et al., 2006; Lenzenweger, Lane, Loranger \& Kessler, 2007), although some estimates are several times higher (Levy, 2013). While the problems of BPD peak in early adulthood after which they can remit, for a sizable minority with the disorder a chronic pattern of problems becomes entrenched throughout adulthood (Kjear et al., 2016; Zanarini, Frankenburg, Reich, \& Fitsmaurice, 2012). There are frequent delays in the diagnosis and treatment of BPD in adult mental health services, representing a failure to halt the progression of the disorder and the associated premature mortality, chronic illness, and disability (Chanen, Sharp, \& Hoffman, 2017; Singh et al., 2010).

Dialectical Behaviour Therapy (DBT), a multi-modal psychosocial treatment with individual therapy, group skills training, between-session telephone support, and therapist consultation, was originally developed for reducing recurrent suicidal and self-harming behaviours (Linehan, 1993; Neacsiu, Ward-Ciesielski, \& Linehan, 2012). Many of McGorry et al.'s (2013) criteria for desirable characteristics of EI programmes are shared by DBT (e.g. long treatment duration, case management strategies, individual and group support, liaison with the system, a focus on the general quality of life etc). DBT is effective in the treatment of BPD with more than a dozen favourable randomised controlled trials (Stoffers et al., 2012; Miga, Neacsiu, Lungu, Heard, \& Dimeff, In press) and DBT has been adapted for agespecific populations, including adolescents (MacPherson, Chavens, Fristad, 2013; Melhum et al., 2014) and college students (Chugani, 2017; Pistorello, Fruzzetti, MacLane, Gallop, \& Iverson, 2012). 
Despite advocacy for EI programmes targeted at young adults living with BPD (Chanen et al., 2017), few data are available on DBT specifically for young adults outside of college counselling service settings. Our study is the first to compare outcomes for a dedicated DBT programme for young adults with young adults who accessed DBT through a general adult DBT programme open to all ages over 18 , the usual context of service delivery to this age group in adult settings. 


\section{Method}

\section{Design}

The study used a non-equivalent, naturally occurring quasi-experimental design which compared outcomes for 18 to 25 years with BPD following one year of treatment in either a dedicated young adult only DBT programme or a general adult DBT programme for all ages 18 and above. Discharge rates from mental health services at 24 months post-treatment completion were also compared across treatment conditions.

The main inclusion criteria for both conditions was an age between 18 and 25 years and a diagnosis of BPD (APA, 2013), typically made previously by a treating psychiatrist in the community. While scores on the Borderline Symptom List 23 (BSL23: Bohus et al., 2009 , see below) were not used to determine inclusion in the study, $89.2 \%$ of participants had a baseline BSL23 score of at least 2.00 and $41.5 \%$ had a score of at least 3.00, consistent with the presence of BPD (Glenn, Weinberg \& Klonsky, 2009). Exclusion criteria mirrored those of the DBT teams, namely an enduring psychotic disorder or primary alcohol or substanceabuse disorder.

\section{Settings}

Data were collected by two established community DBT teams based in different statutory community adult mental health services in Ireland.

\section{Participants}

Data collection took place between September 2013 and August 2016. In total, there were 37 participants, $78.4 \%$ (29) female and $21.6 \%$ (8) males, average age 20.8 years. Twenty-four participants received support in the young adult only DBT condition and 13 participants received support in the general adult DBT condition (see Table 1 for demographic and clinical characteristics). Comparisons of all participant characteristics at baseline across 
conditions were carried out using independent-sample t-tests for continuous variables and chi-square tests of independence for categorical variables. No significant differences were found with the exception of previous hospitalisation, where there was a higher incidence of previous hospitalisation among participants in the general DBT condition. $\left(\chi^{2}=13.46, p\right.$ $<.01)$.

(insert Table 1. about here)

\section{Treatment conditions}

Treatment was standard DBT for both conditions: One hour of weekly individual DBT therapy, 2.5 hours of weekly skills training with two skills trainers, weekly therapist consultation meetings, and between-session telephone coaching. The DBT skills training curriculum used was "Schedule 1: 24 Weeks, Linehan Standard Adult DBT Skills Training Schedule" (Linehan, 2015, pp. 110-111). DBT in both conditions was offered for one year and delivered as an open, rolling programme where participants could enter for one year of treatment at the beginning of any new skills module (thus, skills training groups typically had a mixture of experience levels among participants). DBT was supplementary to existing routine care in the community which typically consisted of outpatient reviews by a consultant psychiatrist, psychiatric registrar, or family doctor every two to three months.

Treatment conditions differed in that the young adult only DBT condition was offered exclusively to 18 to 25 year olds, whereas the general adult DBT condition accommodated adults 18 years and older and skills groups were comprised of a wide age group. Although this study includes only 18 to 25 year olds who accessed the general DBT programme, the age range of all patients in the general adult programme over the study period was 18 to 56 years $(\bar{x}=31.9$ years, $S=9.2)$ of which $32.5 \%(13)$ were between 18 and 25 years. 


\section{Therapists and treatment fidelity}

Therapists across both conditions, consisting of psychologists, social workers, and nurses, had completed no less than ten days standard training in DBT. Formal rating of fidelity to the treatment model was not carried out due to logistical and financial constraints. However, all therapists attended weekly DBT peer-consultation meetings which were intended to promote treatment fidelity through peer-monitoring and encouragement (Linehan, 1993), as well as regular evaluation and feedback by the first author, an accredited DBT therapist and DBT trainer.

\section{Self-report measures, dropout, and discharge}

Borderline symptom severity. The Borderline Symptom List 23 (BSL23; Bohus et al., 2009).

General psychopathology. Global Severity Index on the Symptom Checklist-90Revised (SCL-90-R:GSI; Derogatis, 1994).

Hopelessness. Beck Hopelessness Scale (BHS; Beck, Weissman, Lester, \& Trexler, 1974).

Suicide ideation. Beck Scale for Suicide Ideation (SSI; Beck \& Steer, 1991).

Dropout. Recorded when participants were prematurely discharged from treatment by their DBT team after missing either skills group and/or individual DBT therapy for four weeks in a row, consistent with the 'four miss rule' in DBT (Linehan, 1993).

Service discharge at 24 months post-treatment completion. Recorded when participants were no longer in receipt of any community mental health services 24 months after completing DBT. We did not have ethical approval to collect further data once participants had been discharged. 


\section{Classification of outcome}

We classified outcomes in two ways. The first used post-treatment scores on outcome measures. The second was whether a participant achieved individual change on each selfreport measure using Jacobson and Truax's (1991) reliable change index, calculated with software developed by Morley and Dowzer (2014). The index is based on changes between baseline and post-treatment on each measure, instrument reliability, and clinical and nonclinical distributions on the measure. Participants were categorised as 'no change', 'deteriorated', 'improved', or 'recovered'. No change is defined as individual change between baseline and post-treatment on the measure of less than \pm 1.96 standard deviations from the sample baseline mean score adjusted for measurement error. Deterioration or improvement (i.e. negative or positive reliable change) is defined as individual change between baseline and post-treatment equal or exceeding \pm 1.96 standard deviations from the sample mean score adjusted for error. Recovery (i.e. clinically significant change) is defined as the presence of positive reliable change plus a post-treatment score closer to the mean of healthy controls than the clinical population. The original validation studies were used for establishing normative data for each of the measures in addition to data on adults with BPD where available. The deteriorated or improved indices, recovery cut-offs, and sources of normative data were as follows: BSL23 (deteriorated or improved $= \pm .32$, recovered $\leq .72$; Bohus et al., 2009); SCL-90-R:GSI (deteriorated or improved $= \pm .41$, recovered $\leq .69$; Derogatis, 1994; Schulz et al., 2008); BHS (deteriorated or improved $= \pm 2.97$, recovered $\leq$ 6.64; Beck \& Steer, 1988; Verardi, Nicastro, McQuillan, Keizer, \& Rossier, 2008; Greene, 1981); SSI (deteriorated or improved $= \pm 6.95$, recovered $\leq 1.55$; Beck, Kovacs $\&$ Weissman, 1979; Beck, Steer, \& Brown, 1997). 


\section{Data analysis}

Analysis of the data was conducted using SPSS version 22.0 (IBM Corp, 2013). A series of one-way between-group analyses of covariance (ANCOVA) were carried out to compare participants' post-treatment scores on each of the self-report measures across treatment conditions, with pre-treatment scores on the respective measure and previous hospitalisation (which was significantly different across treatment conditions at baseline) as covariates. Additionally, a series of Fisher's exact tests were carried out to compare the proportion of individual participants who were either at least improved or recovered on each self-report measures across conditions. Fisher's exact tests were also used to compare dropout and discharge rates at 24 months post-treatment across conditions.

\section{Procedure}

During the study period patients offered DBT by the two teams were invited to participate in the study, all of whom consented. No payment was available for involvement in the study. Participants could withdraw from the research at any time with no effect on treatment availability, decisions around which were made independently of the research. Baseline demographic and clinical information were collected and participants completed a battery of self-report measures at baseline and again at treatment completion after one year. Service discharge rates at 24 months post-treatment completion were also recorded. Ethical approval for the project was granted by XXXXXXXX (information removed for blind review). The authors have abided by the ethical principles of psychologists and code of conduct as set out by the APA https://www.apa.org/ethics/codes/ 


\section{Results}

\section{Dropout}

There was no difference between the $20.8 \%$ (5) of participants in young adult only DBT and $15.4 \%$ (2) of young adult participants in general adult DBT who dropped out $(p=.526)$.

\section{Comparing post-treatment scores by treatment condition}

ANCOVA found significant effects for treatment condition on borderline symptom severity and general psychopathology after controlling for covariates, with lower post-treatment scores on BSL23 and SCL-90-R:GSI in the young adult programme (Table 2). Applying

Cohen's (1988) criteria to partial eta squared $\left(\eta_{\mathrm{p}}^{2}\right)$, there was a large effect size for condition on both measures: $16 \%$ of the variance of post-treatment BSL23 scores and $15 \%$ of the variance in the post-treatment SCL-90-R:GSI scores were explained by treatment condition. No post-treatment differences were found across conditions on hopelessness and suicide ideation.

(insert Table 2. about here).

\section{Comparing individual change by treatment condition}

No differences were found in the proportion of participants who showed at-least improvement (i.e. improved or improved + recovered) on any self-report measure across treatment conditions: BSL23 $(p=.126)$, SCL-90-R: GSI $(p=.091)$, BHS $(p=.515)$, and SSI $(p=.579)$. However, a greater proportion of participants were recovered on borderline symptom severity $(p=.046)$ and general psychopathology $(p=.025)$ following one year of treatment in the young adult DBT programme. There were no differences across conditions in the proportion of participants who were recovered on hopelessness $(p=.500)$ and suicide ideation $(p=.571)$.

(insert Figure 1. about here). 


\section{Service Discharge}

$78.9 \%$ (15) completers of young adult only DBT were discharged from community mental health services 24 months following the end of treatment compared with $36.4 \%$ (4) completers of general adult DBT $(p=.047)$. 


\section{Discussion}

We found better outcomes on borderline symptom severity and general psychopathology among young adults with BPD who completed one year of DBT through an EI-informed young adult only DBT compared to the same age group who undertook one year of a general adult DBT accessible to all ages $18+$. No differences between treatment conditions were found for hopelessness, suicide ideation, and dropout. Low dropout for young adults in both programmes (20.8\% and $15.4 \%$ respectively) was surprising since younger age has been associated with higher dropout for adults in DBT (Landes, Chalker, \& Comtois, 2016), and suggests high dropout is not inevitable for young adults in DBT. We also found a greater proportion of completers of the young adult DBT programme had been discharged from services two years later. While discharge rates are a crude marker of remission, they offer a tentative indication that benefits conferred by the young adult DBT programme were maintained during the age range where BPD symptoms otherwise typically peak (Zanarini et al., 2012).

Our findings offer support for the view that EI may be helpful for BPD (Chanen et al., 2017), and are especially encouraging given the seriousness of the disorder (Kjear et al., 2016). By some distance DBT has accumulated the largest evidence-base as a treatment for adults with BPD and compares at least as well to other specialised treatments for BPD (ChoiKain, Albert \& Gunderson, 2016; Miga, Neacsiu, Lungu, Heard \& Dimeff, In press; Stoffers et al., 2012). In describing an advantage for providing DBT to young adults within an agespecific programme, our study points to a straightforward means of making a good treatment potentially work better for this age group.

The design challenges associated with conducting research in community settings greatly constrains our ability to infer factors which may have contributed to these outcomes. Since the model of therapy was the same across conditions, we are led to cautiously speculate 
that non-specific therapeutic factors (i.e. those not directly related to the treatment protocol) contributed to the difference in outcomes. Group membership characteristics most clearly differentiate the conditions, where the dedicated young adult programme involved weekly skills group training among age-similar peers compared to the general adult programme where the group membership consisted of a wide age range from 18 to 56 years. While the individual therapeutic alliance in DBT has received some attention (Bedics, Atkins, Harned \& Linehan, 2015), little research has been carried out on group factors in DBT. Cohesion is a commonly studied group process, a complex construct related to bond and task focus in the group and comprises myriad relationships (e.g., leader to member, member to member, and leader to leader; Burlingame \& McClendon-Theobald, 2008). Cohesion has been related to patient improvement in groups, especially for groups longer than 12 sessions and with five to nine members (Burlingame, Theobald-McClendon \& Alonso, 2011), consistent with both treatment conditions. However, group cohesion can be enhanced by similarities among group members (Dunlop \& Beauchamp, 2011), and in particular by similar ages among younger people (Burlingame et al., 2011). Consistent with this, the first author recalls many more anecdotes offered by therapists providing young adult DBT relating to group belonging and togetherness.

Our study suffers from significant methodological weaknesses. These include small sample size, sole reliance on self-report instruments to measure outcome, the absence of a formal diagnostic interview at pre-treatment, exclusion of dropouts from the analysis, and no formal measurement of treatment fidelity. In addition, participants were neither randomly nor evenly allocated to treatment conditions, delivered by two separate teams. This creates a serious concern which cannot be ruled out within our design that outcomes reflect differences between participant groups (although our analyses did control for baseline scores on outcomes) or the treating teams rather than the treatment conditions. Notwithstanding these 
limitations, a notable strength of our study is that this represents a first effort to systematically investigate benefits of DBT when used as an EI for young adults with BPD. Our findings suggest not only improved clinical outcomes for a dedicated young adult DBT programme, but that these may translate into sustained gains reflected in higher service discharge rates several years later, consistent with the primary objectives of EI to curb the trajectory of chronic and disabling illness (McGorry et al., 2013; 2014).

DBT for young adults with BPD warrants further evaluation using a randomised controlled trial design, including long term follow up and an evaluation of cost effectiveness. In addition, the study raises questions about mechanisms of change in DBT, in particular the possible contribution made by some group factors. 


\section{Conflict of Interest}

The first and second author receive payment for the delivery of training in DBT. The remaining authors have no conflict of interest with respect to this publication

\section{Financial Support}

This research received no specific grant from any funding agency, commercial or not-forprofit sectors. 


\section{References}

American Psychiatric Association. (2013). Diagnostic and statistical manual of mental disorders $\left(5^{\text {th }} e d\right)$. Washington, DC: Author.

Bateman, A.W., \& Krawitz, R. (2013). Borderline personality disorder: An evidence-based guide for generalist mental health professionals. Oxford, UK: Oxford University Press.

Beck, A.T., Kovacs, M., \& Weissman, A. (1979). Assessment of suicide intention: The scale for suicide ideation. Journal of Consulting and Clinical Psychology, 47, 343-352.

Beck, A. T., \& Steer, R. A. (1988). Manual for the Beck Hopelessness Scale. San Antonio, TX: Psychological Corporation.

Beck, A. T., \& Steer, R. A. (1991). Manual for the Beck Scale for Suicide Ideation. San Antonio, TX: Psychological Corporation.

Beck, A.T., Steer, R.A., \& Brown, G. (1997). Dysfunctional attitudes and suicidal ideation in psychiatric outpatients. Suicide and Life-threatening Behaviour, 23, 11-20.

Beck, A. T., Weissman, A., Lester, D., \& Trexler, L. (1974). The measurement of pessimism: The Hopelessness Scale. Journal of Consulting and Clinical Psychology, 42, 861-865.

Bedics, J.D., Atkins, D.C., Harned, M.S., \& Linehan, M.M. (2015). The therapeutic alliance as a predictor of outcome in dialectical behaviour therapy versus nonbehavioural psychotherapy by experts for borderline personality. Psychotherapy, 52, 67-77. Bellino, S., Bozzatello, P., \& Bogetto, F. (2015). Combined treatment of borderline personality disorder with interpersonal psychotherapy and pharmacotherapy: Predictors of response. Psychiatry Research, 226, 284-288. 
Birleson, P., Luk, E.S.L., \& Mileshkin, C. (2001). Better mental health services for young people: Responsibility, partnerships and projects. Australian and New Zealand Journal of Psychiatry, 35, 36-44.

Bohus, M., Kleindienst, N., Limberger, M.F., Stieglitz, R.D., Domsalla, M., Chapman, A.L., Steil, R., Philipsen, A., \& Wolf, M. (2009). The short version of the Borderline Symptom List (BSL-23): development and initial data on psychometric properties. Psychopathology, 42, 32-39.

Bohus, M., Limberger, M.F., Frank, U., Chapman, A.L., Kuhler, T., \& Stieglitz, R.D. (2007). Psychometric properties of the borderline symptom list (BSL). Psychopathology, 40, 126-132.

Burlingame, G.M., Fuhriman, A., \& Johnson, J. (2001). Cohesion in group psychotherapy. Psychotherapy, 38, 373-379.

Burlingame, G.M., Fuhriman, A., \& Johnson, J.E. (2011). Cohesion in group psychotherapy. In J. Norcross (Ed.), Psychotherapy relationships that work: Evidence-based responsiveness ( $2^{\text {nd }}$ ed., pp. 110-131). Oxford University Press: New York.

Burlingame, G.M., \& McClendon-Theobald, D. (2008). Group therapy. In. J.L. Lebow. (Ed.), Twenty first century psychotherapies: Contemporary approaches to theory and practice. (pp. 347-38). Hoboken, New Jersey: John Wiley \& Sons, Inc.

Burlingame, G.M., Thoebald, D.T., \& Alonso, J. (2011). Cohesion in group therapy. Psychotherapy, 48, 34-42.

Chanen, A.M., Sharp, C., \& Hoffman, P. (2017). Prevention and early intervention for borderline personality disorder: a novel public health priority. World Psychiatry, 16, 215-216. 
Choi-Kane, L.W., Albert, E.B., \& Gunderson, J.G. (2016). Evidence-based treatments for borderline personality disorder: Implementation, integration, and stepped care. Harvard Review of Psychiatry, 5, 342-356.

Chugani, C. (2017). Adapting dialectical behaviour therapy for college counselling centres. Journal of College Counselling, 20, 67-80.

Cohen, J.W. (1988). Statistical power analysis for the behavioural sciences $\left(2^{\text {nd }}\right.$ ed.) Lawrence Erlbaum Associates: Hillsdale, NJ.

Coid, J., Yang, M., Tyrer, P., Roberts, A., \& Ullrich, S. (2006). Prevalence and correlates of personality disorder in Great Britain. British Journal of Psychiatry, 188, 423-431.

Derogatis, L.R. (1994). Symptom Checklist-90-R: Administration, scoring, and procedures manual ( $3^{\text {rd }}$ ed.). Minneapolis, MS: Pearson.

Dunlop, W.L., \& Beauchamp, M.R. (2011). Does similarity make a difference? Predicting cohesion and attendance behaviours within exercise group settings. Group dynamics: Theory, research and practice, 15, 258-266.

Eckersley, R. (2011). Troubled youth: An island of misery in an ocean of happiness, or the tip of an iceberg of suffering? Early Intervention in Psychiatry, 5 (Suppl. 1), 6-11.

Edlund, M.J., Wang, P.S., Berglund, P.A., Katz, S.J., Lin, E., \& Kessler, R.C. (2002). Dropping out of mental health treatment: Patterns and predictors among epidemiological survey respondents in the United States and Ontario. American Journal of Psychiatry, 159, $845-851$.

Greene, S.M. (1981). Levels of measured hopelessness in the general population. British Journal of Clinical Psychology, 20, 11-14. 
Hegelstad, W.T., Larsen, T.K., Auestad, B., Evensen, J., Haahr, U., Joa, I., Johannesen, J.O., Langeveld, J., Melle, I., Opjordsmoen, S., Rossberg, J.I., Rund, B.R., Simonsen, E., Sundet, K., Vaglum, P., Friis, S., \& McGlashan, T. (2012). Long-term follow-up of the TIPS early detection in psychosis study: Effects on 10-year outcome. American Journal of Psychiatry, 169, 374-380.

IBM Corp. (2013). IBM SPSS Statistics for Windows, Version 22.0. Armonk, NY: IBM Corp.

Iverson, K.M., Follette, V.M., Pistorello, J., \& Fruzzetti, A.E. (2012). An investigation of experiential avoidance, emotion dysregulation, and distress tolerance in young adult outpatients with borderline personality disorder symptoms. Personality Disorders: Theory, Research, and Treatment, 3, $415-244$.

Jackson, H.J., \& McGorry, P.D. (2009). The recognition and management of early psychosis: A preventive approach ( $2^{\text {nd }}$ ed.). Cambridge, United Kingdom: Cambridge University Press.

Jacobson, N.S., \& Truax, P. (1991). Clinical significance: a statistical approach to defining meaningful change in psychotherapy research. Journal of Consulting and Clinical Psychology, 59, 12-19.

Kessler, R., Berglund, P., Demler, O., Jin, R., Merikangas, K., \& Walters, E. (2005). Lifetime prevalence and age-of-onset distributions of DSM-IV disorders in the national comorbidity survey replication. Archives of General Psychiatry, 62, 593-602.

Kjaer, J.N., Biskin, R., Vestergaard, C., Gustafsson, L.N., \& Munk-Jorgensen, P. (2016). The clinical trajectory of patients with borderline personality disorder. Personality and Mental Health, 10, 181-190. 
Landes, S.J., Chalker, S.A., \& Comtois, K.A. (2016). Predicting dropout in outpatient dialectical behaviour therapy with patients with borderline personality disorder receiving psychiatric disability. Borderline Personality Disorder and Emotion Dysregulation, 3:9. Doi: 10.1186/s40479-016-0043-3

Lenzenweger, M.F., Lane, M.C., Loranger, A.W., \& Kessler, R.C. (2007). DSM-IV personality disorders in the National Comorbidity Survery Replication. Biological Psychiatry, 15, $553-564$.

Linehan, M.M. (1993). Cognitive-behavioural treatment of borderline personality disorder. Guilford Press: London.

Linehan, M.M. (2015). DBT skills training manual (2 $\left.{ }^{\text {nd }} e d\right)$. London: Guilford Press.

Lyons, P.S., \& Melton, G.B. (2005). Coping with mental health problems in young' adulthood: Diversity of need and uniformity of programmes. In. D.W. Osgood, E.M. Foster, C. Flanagan, \& R. Gretchen (Eds). On your own without a net: The transition to adulthood for vulnerable populations (pp. 304-322). Chicago, IL: The University of Chicago Press.

MacPherson, H.A., Chavens, J.S., \& Fristad, M.A. (2013). Dialectical behaviour therapy for adolescents: Theory, treatment adaptations, and empirical outcomes. Clinical Child and Family Psychological Review, 16, 59-80.

McGorry, P.D. (2011). Transition to adulthood: The critical period for pre-emptive, diseasemodifying care for schizophrenia and related disorders. Schizophrenia Bulletin, 37, 524-530.

McGorry, P.D. (2015). Early intervention with psychosis: Obvious, effective, overdue. The Journal of Nervous and Mental Disease, 203 (5), 310-318. 
McGorry, P.D., Bates, T., \& Birchwood, M. (2013). Designing youth mental health services for the 21st century: Examples from Australia, Ireland and the UK. British Journal of Psychiatry, 54, s30-s35.

McGorry, P.D., Goldstone, S.D., Parker, A.G., Rickwood, D.J., \& Hickie, I.B. (2014). Cultures of mental health care of young people: an Australian blueprint for reform. Lancet Psychiatry, 1, 559-568.

Melhum, L., Tormoen, A.J., Ramberg, M., Haga, E., Diep, L.M., Laberg, S., Larsson, B.S., Stanley, B.H., Miller, A.L., Sund, A.M., \& Grohold, B. (2014). Dialectical behaviour therapy for adolescents with repeated suicidal and self-harming behaviour: a randomised trial. Journal of the American Academy of Child and Adolescent Psychiatry, 53, 1082-1091.

Miga, E.M., Neacsiu, A.D., Lungu, A., Heard, H.L., \& Dimeff, L.A. (In press). Dialectical behaviour therapy from 1991-2015: What do we know about clinical efficacy and research quality? In. M.A. Swales (Ed.). Oxford handbook of dialectical behaviour therapy. Oxford: Oxford University Press.

Moran, P., Coffey, C., Romaniuk, H., Olsson, C., Borshmann, R., Carlin, J.B., \& Patton, G.C. (2012). The natural history of self-harm from adolescence to adulthood: A populationbased cohort study. Lancet, 379, 236-243.

Morley, S., \& Dowzer, C.N. (2014). Manual for the Leeds Reliable Change Indicator: Simple Excel® applications for the analysis of individual patient and group data. University of Leeds, Leeds, UK

Murcott, W.J. (2014). Transitions between child and adult mental health services: Service design, philosophy and meaning at uncertain times. Journal of Psychiatric and Mental Health Nursing, 21, 628-634. 
Neacsiu, A.D., Ward-Ciesielski, E.F., \& Linehan, M.M. (2012). Emerging approaches to counselling intervention: Dialectical behaviour therapy. The Counselling Psychologist, 40, 1003-1032.

Patton, G. (1996). An epidemiological case for a separate adolescent psychiatry. Australian and New Zealand Journal of Psychiatry, 30, 563-566.

Paul, M., Street, C., Wheeler, N., \& Singh S.P. (2015). Transition to adult services for young people with mental health needs: A systematic review. Clinical Child Psychology and Psychiatry, 20 (3), 436-457.

Pistorello, J., Fruzzetti, A.E., MacLane, C., Gallop, R., \& Iverson, K.M. (2012). Dialectical behaviour therapy (DBT) applied to college students: A randomised clinical trial. Journal of Consulting and Clinical Psychology, 80, 982-994.

Reneses, B., Munoz, E., \& Lopez-Ibor, J.J. (2009). Factors predicting drop-out in community mental health centres. World Psychiatry, 8 (3), 173-177.

Schulz, S.C., Zanarini, M.C., Bateman, A., Bohus, M., Detke, H.C., Trzaskoma, Q., Tanaka, Y., Lin, D., Debredt, W., \& Corya, S. (2008). Olanzapine for the treatment of borderline personality disorder: variable dose 12-week randomised double-blind placebo-controlled study. The British Journal of Psychiatry, 193, 485-492.

Singh, S.P., Paul, M., Ford, T., Kramer, T., Weaver, T., McLaren, S., Hovish, K., Islam, Z., Belling, R., \& White, S. (2010) Process, outcome and experience of transition from child to adult mental healthcare: multiperspective study. British Journal of Psychiatry, 197, 305-312. 
Stoffers, J.M., Völlm, B.A., Rücker, G., Timmer, A., Huband, N., \& Lieb, K. (2012). Psychological therapies for people with borderline personality disorder. Cochrane Database of Systematic Reviews 8, doi:10.1002/14651858.CD005652.pub2.

Veradi, S., Nicastro, R., McQuillan, A., Keizer, I., \& Rossier, J. (2008). The personality profile of borderline personality disordered patients using the five-factor model of personality. International Journal of Clinical and Health Psychology, 8, 451-464.

Wampold, B.E., \& Imel, Z.E. (2015). The great psychotherapy debate (2 ${ }^{\text {nd }}$ ed.). London: Routledge.

WHO (1992). The ICD-10 classification of mental and behavioural disorders: Clinical descriptions and diagnostic guidelines. Geneva: WHO.

Zanarini, M.C., Frankenburg, F.R., Reich, D.B., \& Fitsmaurice, G. (2012). Attainment and stability of sustained symptomatic remission and recovery among patients with borderline personality disorder and axis II comparison subjects: A 16-Year prospective follow-up study. American Journal of Psychiatry, AiA, 
Table 1. Demographic and clinical characteristics of participants. Data are given as a percentage (number) unless otherwise specified.

\begin{tabular}{lccc}
\hline Variable & Young adult only & General adult & All \\
DBT & DBT &
\end{tabular}

\begin{tabular}{lccccccc}
\hline Demographic Characteristics & \multicolumn{2}{c}{$\mathrm{n}=24$} & \multicolumn{2}{c}{$\mathrm{n}=13$} & \multicolumn{2}{c}{$\mathrm{N}=37$} \\
Age, mean (SD) & 20.50 & $(1.91)$ & 21.46 & $(2.15)$ & 20.84 & $(2.02)$ \\
Gender: & & & & & & \\
Female & $83.3 \%$ & $(20)$ & $69.2 \%$ & $(9)$ & $78.4 \%$ & $(29)$ \\
Male & $16.7 \%$ & $(4)$ & $30.8 \%$ & $(4)$ & $21.6 \%$ & $(8)$
\end{tabular}

Education:

$\begin{array}{llllll}\text { Second level only } & 29.2 \% & (7) & 38.5 \% & (5) & 32.4 \% \\ \text { Some post-second level } & 70.8 \% & (17) & 61.5 \% & (7) & 64.9 \%\end{array}$

Employment:

$\begin{array}{llllll}\text { Employed/In education } & 66.7 \% & (16) & 46.2 \% & (6) & 59.5 \% \\ \text { Unemployed } & 33.3 \% & (8) & 53.8 \% & (7) & 40.5 \%\end{array}$

\section{Pre-existing Clinical Diagnoses}

BPD

Eating disorder

PTSD

Addiction (alcohol or drugs)
$100 \%$

(24)

$41.7 \%$

(10)

$29.2 \%$

$12.5 \%$

(3)

$100 \%$

(13)

$100 \%$

\section{History of High Risk Behaviours}

\begin{tabular}{lllllll} 
Previous suicide attempt & $54.2 \%$ & $(13)$ & $61.5 \%$ & $(8)$ & $56.8 \%$ & $(21)$ \\
History of self-injury & $70.8 \%$ & $(17)$ & $76.9 \%$ & $(10)$ & $73.0 \%$ & $(27)$ \\
Use of ED due to self-injury & $37.5 \%$ & $(9)$ & $53.8 \%$ & $(7)$ & $43.2 \%$ & $(16)$ \\
\hline Mental Health Service Use & & & & & & \\
Previous hospitalisation & $25.0 \%$ & $(6)$ & $53.8 \%$ & $(7)$ & $35.1 \%$ & $(13)$ \\
Previous therapy & $83.3 \%$ & $(20)$ & $69.2 \%$ & $(9)$ & $78.4 \%$ & $(29)$ \\
Currently taking medication & $70.8 \%$ & $(17)$ & $84.6 \%$ & $(11)$ & $75.7 \%$ & $(28)$
\end{tabular}



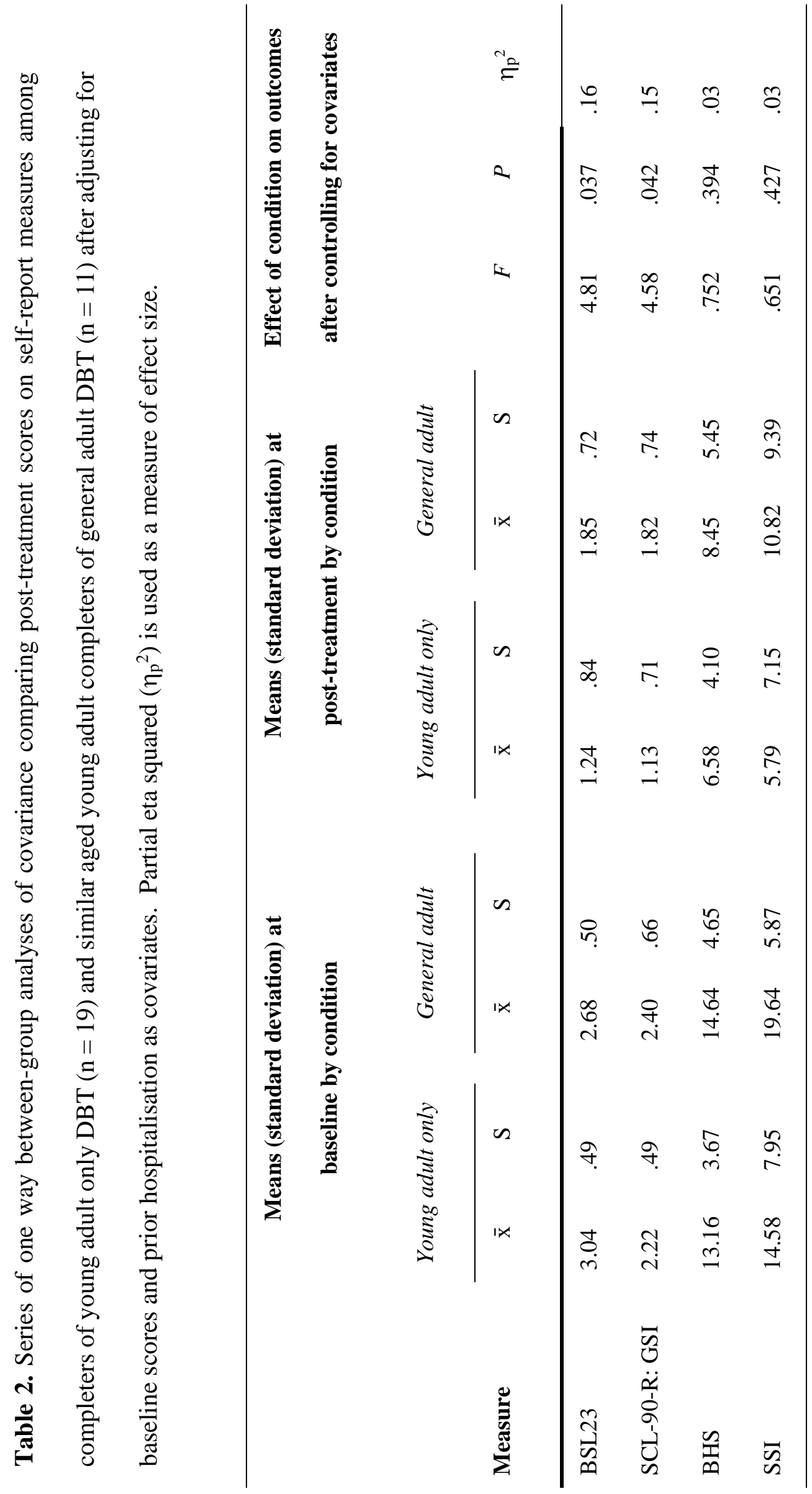
Classification (\%) of individual change on borderline symptom severity (BSL23)
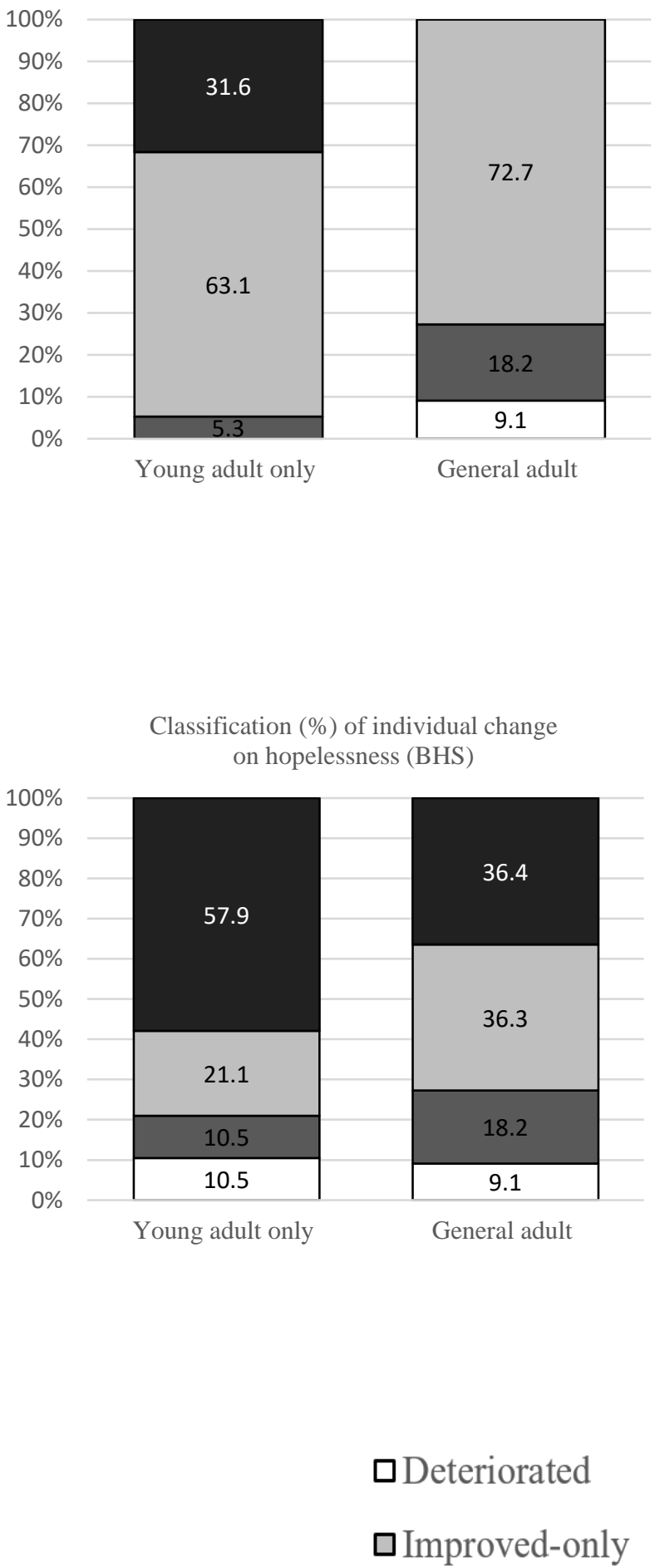

Classification (\%) of individual change on hopelessness (BHS)

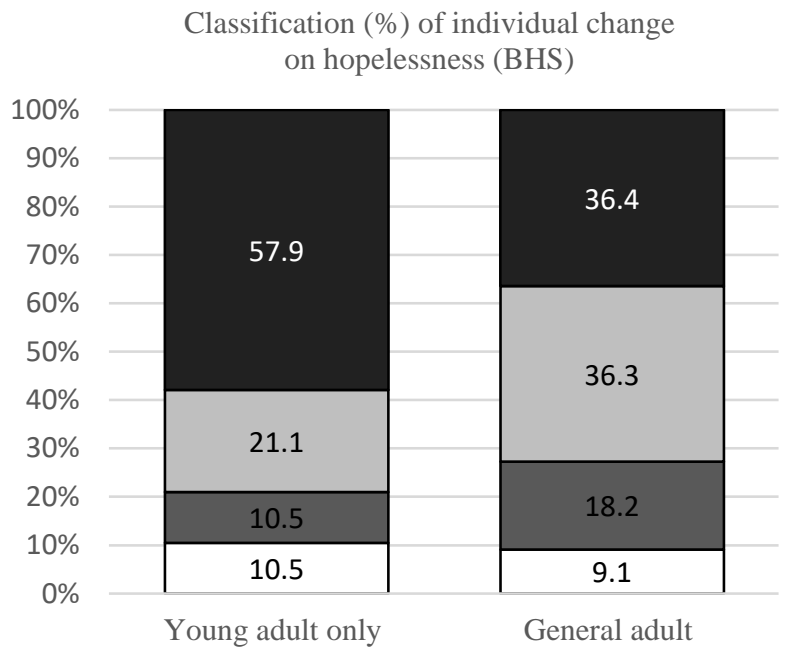

Gimproved-only
Classification (\%) of individual change on general psychopathology (SCL-90-R: GSI)

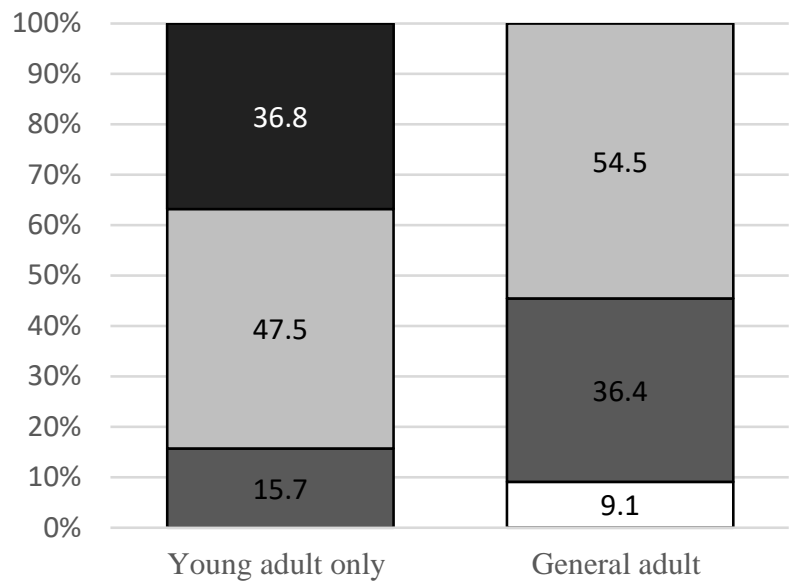

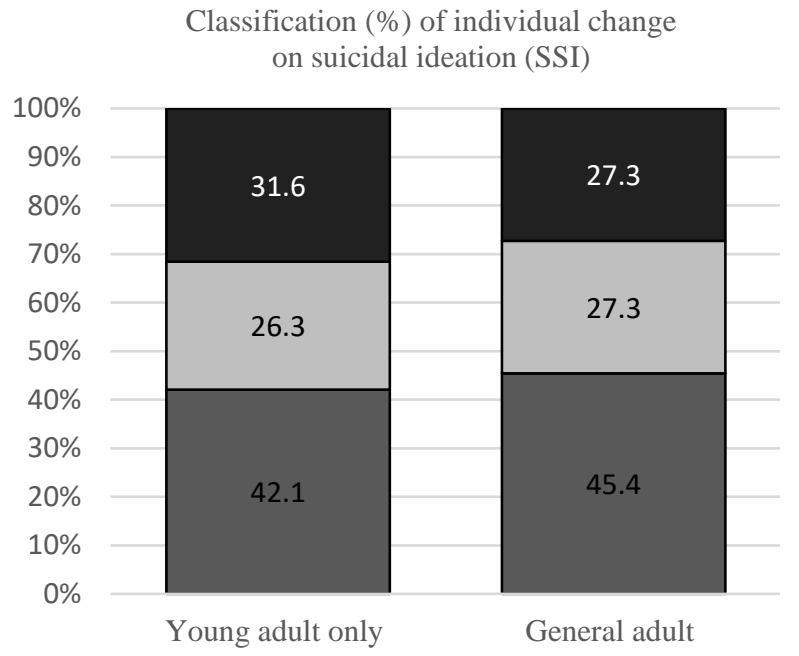

$\square$ No change

a Recovered

Figure 1. Classification of individual change on measures among one year completers using Jacobson and Truax's (1991) reliable change procedure by treatment condition, young adult only DBT programme $(n=19)$ and young adults in general adult DBT $(n=11)$. 